\title{
Control of Small Grid-connected Photovoltaic Power Generation System Based on Micro-inverter
}

\author{
Li Chunlai $^{1}$, Liu Weiliang ${ }^{2}$ a $^{*}$, Wang Yinsong ${ }^{2}$, Lin Yongjun ${ }^{2}$, Liu Changliang ${ }^{2}$ \\ ${ }^{1}$ Key Laboratory of Grid-Connected Photovoltaic Technology, Electric Power Research Institute of \\ Qinghai Power Grid Corporation, Xining, Qinghai, 810008 China \\ ${ }^{2}$ Department of Automation, North China Electric Power University, Baoding, Hebei,071003 China \\ aemail:Iwlfengzhiying@163.com
}

Keywords: Photovoltaic Power Generation, Grid-connected Operation without Power Injection, Micro-inverter, Maximum Power Point Tracking (MPPT)

Abstract. In this paper, a small photovoltaic power generation system based on micro-inverter is introduced. In order to overcome the shortcomings of stand-alone mode and grid-connected mode, an operating method is presented. The system is parallel with the single-phase grid to enable grid-connected operation without power injection. Simulation results show that the system could steadily work in two different modes, improve the efficiency of power generation, and reduce the impact to power grid.

\section{Introduction}

Photovoltaic power generation has been widely used in recent years, along with the rapid growth of the world energy demand and gradually reduction of fossil energy [1],[2]. The operation mode could be mainly divided into independent operation and parallel operation. For independent operation, the system is not connected to the power grid, and supply power alone to nearby users. In order to ensure the continuity of power supply, configuration of battery is necessary, which will cause higher maintenance cost, and the impropriety to spread to areas covered by power grid; for parallel operation, the system is connected to the power grid and energy is transported to power grid directly without configuration of battery. Because ordinary parallel mode is not coordinated with local load, voltage fluctuations may occur at the end of power grid when sunlight changes greatly, which causes impulse impaction to power grid. In order to overcome the disadvantages of the above two kinds of operation mode, in this paper, one kind of grid-connected operation mode without power injection is presented.

Moreover, in the existing photovoltaic power generation system, several PV modules are usually connected in series-parallel for the sake of getting higher voltage and power levels, and then output power through a larger capacity inverter. However, it is difficult to ensure that they are all working at the maximum power point due to the characteristic difference among PV modules, which causes power loss. In recent years, scholars present the concept of micro-inverter that is suitable for single PV module, and could dramatically improve the efficiency of power generation because it is able to ensure each module is working at maximum power point [3], [4].

\section{System Structure and Working Mode}

The presented small photovoltaic power generation system is mainly composed of PV module, micro inverter and local load, as shown in Fig. 1. The micro-inverter mainly includes two parts, the DC/DC converter using flyback topology and the DC/AC converter using MOSFET full-bridge. Functionally, the DC/DC part can achieve boost transformation, maximum power point tracking (MPPT), and it converts the DC output of the solar panels to a half-wave sinusoidal current. The output half-wave sinusoidal current is converted to be full-wave sinusoidal current by the DC/AC part, and then the current is fed to the EMI filter before the grid. Because the energy could flow only in one-way due to the adoption of flyback converter, a secondary load $\mathrm{R}_{\mathrm{z}}$ is added after the flyback converter to assist the voltage control before grid connection. 
System working stage is divided into before grid connection and after grid connection. In the stage of before grid connection, the system works in voltage tracking mode, turn on switch K1, after the amplitude, phase, and frequency of system output voltage is adjusted to be the same as those of grid voltage, turn on switch K2 to connect the system to grid. Right after connection, turn off switch K1, the system enters the stage of after grid connection. In order to ensure the system doesn't output power to grid, the system works in load current tracking mode, that is, when output power of PV cells component is enough for the local load, output current of micro inverter is controlled to tracking the load current; when the output power of PV cells components is not enough for the local load, the micro inverter works at maximum power tracking mode, and the power vacancy is filled up by the grid.

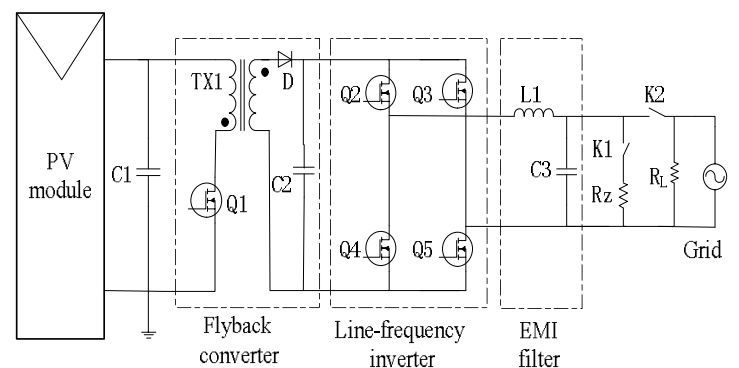

Fig.1. Structure of Small Photovoltaic Power Generation

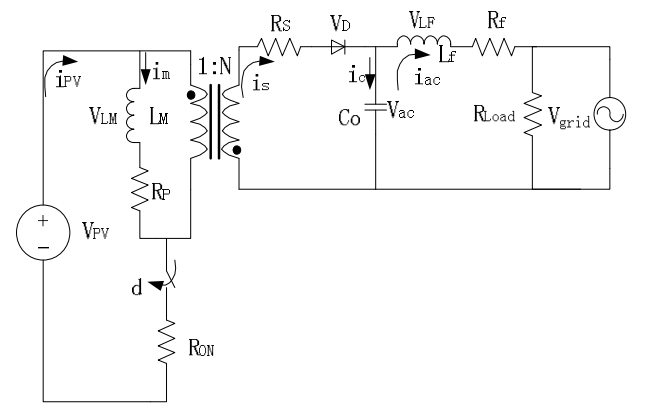

Fig.2 Equivalent Circuit of Micro-inverter

\section{Model of Micro-inverter}

Flyback converter is the core part of the micro inverter, and its equivalent non-isolated circuit is a Buck-Boost converter, which is essentially a highly nonlinear system [5]. In order to facilitate analysis, the grid voltage $\mathrm{V}_{\text {grid }}$ is equivalent to half sine wave, and the system equivalent circuit is shown in Fig. 2. Flyback converter has the following three states that need to be analyzed corresponding to three energy storage elements: flyback inductor current $\mathrm{I}_{\mathrm{m}}$, flyback output capacitor voltage $\mathrm{V}_{\mathrm{ac}}$, System output current $\mathrm{I}_{\mathrm{ac}}$. Assume $\mathrm{d}$ is the duty cycle of modulation signal, $\mathrm{d}^{\prime}$ is the off-time (1-d), $\mathrm{N}$ is the turns ratio of flyback transformer, $\mathrm{X}, \mathrm{U}$ and $\mathrm{Y}$ represent the system static working point, $x, u$, and $y$ are the perturbations over the operating point, the small signal linearized model is obtained, The transfer function is obtained between the output $\mathrm{AC}$ current and modulation input, as shown in Equation (1).

$$
G(s)=\frac{\frac{k D^{\prime}-I_{m} R}{L_{n} N L_{f} C_{o}}-\frac{I_{m}}{L_{n} C_{o} N} s}{s^{3}+\left(\frac{R}{L_{n}}+\frac{R_{f}}{L_{f}}\right) s^{2}+\left(\frac{R R_{f}}{L_{h} L_{f}}+\frac{1}{L_{f} C_{o}}+\frac{D^{2}}{N^{2} L_{n} C_{o}}\right) s+\left(\frac{R}{L_{n} L_{f} C_{o}}+\frac{R_{f} D^{2}}{N^{2} L_{n} C_{o}}\right)}
$$

\section{System Control Strategy}

Control Method Before Grid Connection. In the stage of before grid connection, it is necessary to control the inverter output voltage $V_{o}$ to track the single-phase grid voltage $V_{\text {grid. }}$. At this time, it can be assumed that $R_{\text {load }}=R_{z}$ in Fig. 2. Because the value of $R_{z}$ is quite great, peak of inverter output current $i_{\mathrm{ac}}$ is small. Voltage instantaneous value feedback control method is adopted, and feed forward compensation is added in to improve the stability of the system, as shown in Fig. 3. Feed forward compensation $D$ is calculated according to the relations between input voltage $\mathrm{V}_{\mathrm{pv}}$ and output voltage $\mathrm{V}_{\mathrm{ac}}$ of the flyback converter

$$
D=\frac{V_{g r i d}}{V_{g r i d}+N \cdot V_{p v}}
$$

Control Method After Grid-Connection. In the stage of after grid-connection, when the output power of PV module is sufficient for the local load, output current iac of micro inverter is controlled to tracking the load current iL; when the output power of PV module is insufficient for the local load, the micro inverter works at maximum power tracking (MPPT) mode, and the amplitude set value Iref of 
output current iac is calculated by perturbation and observation (P\&O). Consider the asymmetry of gradient around the MPP in photovoltaic cell P-V curve, in the area on the right side of MPP, smaller output current disturbance step $\Delta \mathrm{I}$ is adopted to ensure the tracking precision; in the area on the left side of MPP, bigger output current disturbance step $\mathrm{K} \bullet \Delta \mathrm{I}(\mathrm{K}>1)$ is adopted to improve the tracking speed, which could reduce the time that photovoltaic cells output low power. Similar to the voltage control mode, instantaneous value feedback combined with feed forward compensation control method is performed to adjust the output current $i_{\text {ac }}$, as shown in Fig. 4.

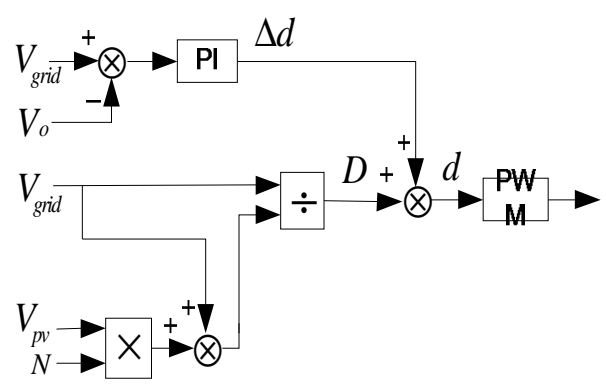

Fig. 3. Control Block Diagram of Voltage

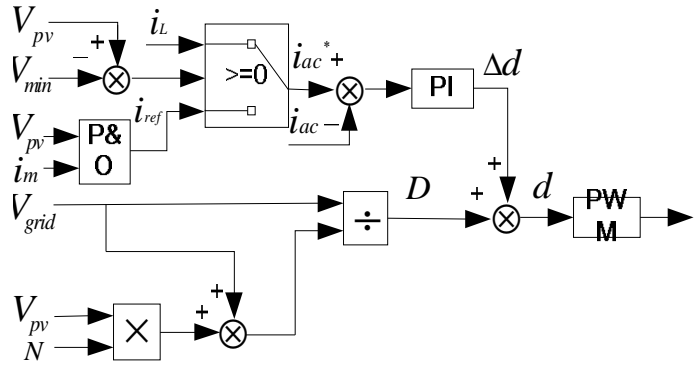

Fig.4. Control Block Diagram of Current

\section{Optimization of PI Controller}

It is known by Equation (1), G(s) changes mainly with the amplitude and phase of Iac. In this paper, select $I_{\text {rms }}=\left\{\frac{1}{3} I_{\text {acmax }}, \frac{2}{3} I_{\text {acmax }}, I_{\text {acmax }}\right\}$ and $\Theta=\left\{30^{\circ}, 60^{\circ}, 90^{\circ}\right\}$ respectively, as a total of nine different static working points to perform the PI controller parameters optimization. Genetic algorithm (GA) is a kind of randomized search method which simulates the evolutionary mechanism. It has the virtues of parallel computing and global convergence, and is suitable for solving optimization problems. So this paper takes the genetic algorithm to optimize the parameters of PI controller.

\section{Simulation of System}

System simulation model is established using Matlab SimElectronics component library, according to the PV module that the laboratory already configured. The parameters of PV module are set as: rated power $\mathrm{P}=235 \mathrm{w}$, open circuit voltage $\mathrm{V}_{\text {oc }}=37 \mathrm{~V}$, short circuit current $\mathrm{I}_{\mathrm{sc}}=8.54 \mathrm{~A}$, maximum power point voltage $\mathrm{V}_{\mathrm{mpp}}=29.5 \mathrm{~V}$, maximum power point current $\mathrm{I}_{\mathrm{mpp}}=7.97 \mathrm{~A}$. Main parameters of the micro inverter are: $\mathrm{L}_{\mathrm{m}}=55 \mathrm{uh}, \mathrm{R}_{\mathrm{p}}=28 \mathrm{~m} \Omega, \mathrm{R}_{\mathrm{on}}=15 \mathrm{~m} \Omega, \mathrm{R}_{\mathrm{s}}=1 \Omega, \mathrm{C}_{\mathrm{o}}=0.017 \mathrm{uF}, \mathrm{L}_{\mathrm{f}}=600 \mathrm{uh}, \mathrm{R}_{\mathrm{f}}=0.61 \Omega$.

Load Current Tracking Mode. Optimization of Current PI controller parameters is performed using Matlab genetic algorithm (GA) toolbox, assign the value range of $K_{\mathrm{p}}$ is $[0,1]$, the value range of $K_{\mathrm{i}}$ is [0,5000], group size is 20 , roulette wheel model is adopted to perform the selection process, the crossover probability is 0.85 , the mutation probability is 0.01 , and optimization results are $K_{\mathrm{p}}=0.22, K_{\mathrm{i}}$ $=860$. Simulation of load suddenly rising $100 \%$ and drop $50 \%$ is performed, as shown in Fig. 5 . It is apparently that inverter output current $i_{\mathrm{ac}}$ is able to track the load current $i_{\mathrm{L}}$ well, and the current injected to gird is approximate to zero, which could eliminate the impaction to grid.

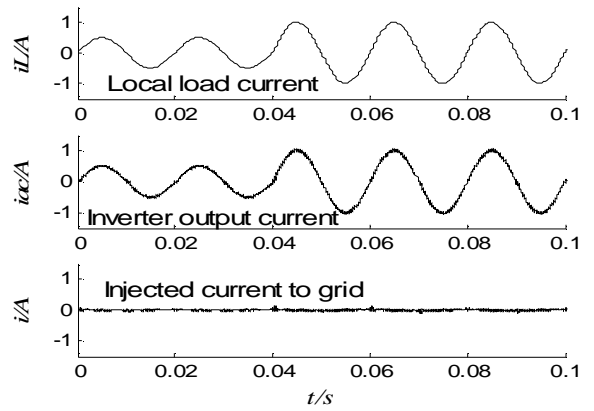

1) Load Current Increase $100 \%$ Suddenly

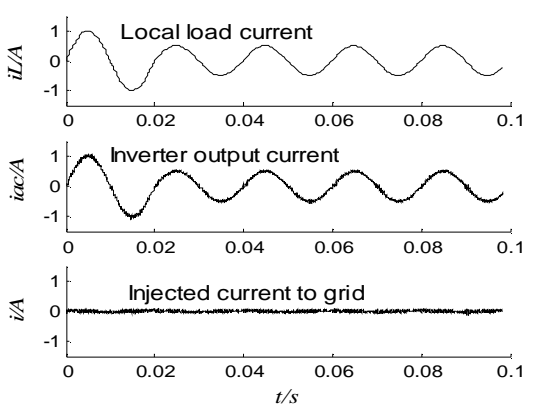

2) Load Current Decrease 50\% Suddenly

Fig. 5. Running Simulation Curve When Load Suddenly Changes 
Maximum Power Tracing Model. Set the parameter $n=2$ in P\&O method, and inverter output current disturbance step $\Delta \mathrm{I}=0.01 \mathrm{~A}, \mathrm{~K}=2$. At initial moment, $t=0 \mathrm{~s}$, light intensity is set as $600 \mathrm{~W} / \mathrm{m}^{2}$, and the light intensity is change to be $800 \mathrm{~W} / \mathrm{m}^{2}$ at the time $t=0.04 \mathrm{~s}$, the tracking process is shown in Fig. 6 . The disturbance period is $0.04 \mathrm{~s}$, after 18 times of disturbance, at the time $t=0.80 \mathrm{~s}$ steady state process is achieved, namely the system enters the oscillation around maximum power point.

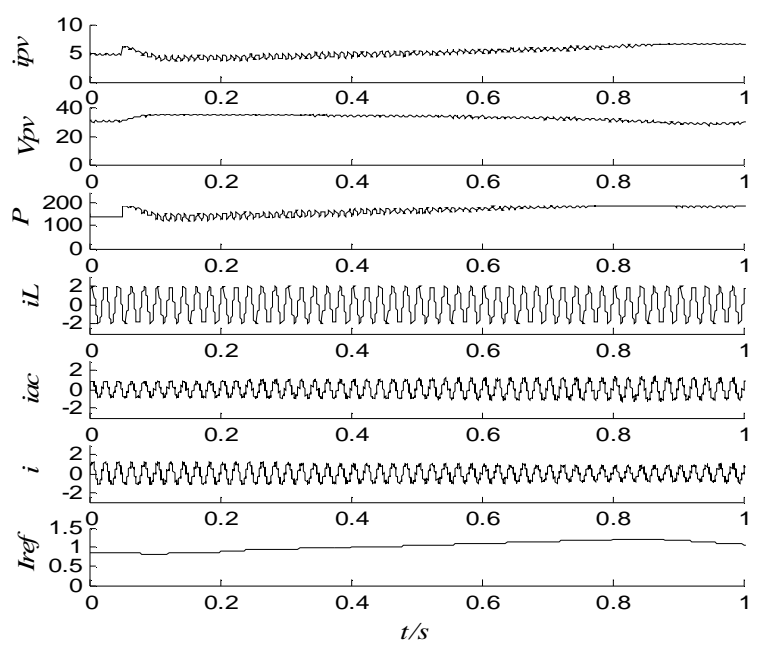

Fig. 6. Simulation Process of MPPT

\section{Summary}

This paper presents one kind of grid-connected operation mode without power injection for small photovoltaic power generation system. In order to improve the control quality, optimization of PI controller parameters is performed based on the mathematical model of flyback type micro inverter. simulation results show that the system could steadily work in the maximum power point tracking mode and load current tracking mode, which is able to effectively improve the power generation efficiency, and reduce the impact to power grid.

\section{Acknowledgment}

The work of this paper is supported by Science and Technology Project of State Grid Corporation of China (2014-Z-Y34A) and "the Fundamental Research Funds for the Central Universities" of North China Electric Power University (2015ZD17).

\section{References}

[1] Honghua X, "The Study on Development of PV Technology in China”, Power System Technology, 2007, Issue:20, pp.77-81.

[2] Hill C.A.;Such M. C.; Chen D. M.; et al., "Battery Energy Storage for Enabling Integration of Distributed Solar Power Generation", Smart Grid,2012,3(2), pp. 850-857.

[3] Haibing Hu, Harb S, Kutkut N, et al. "Power decoupling techniques for micro-inverters in PV systems-a review”, 2010 IEEE Conference on Energy Conversion Congress, 2010, pp. 3235- 3240.

[4] Meshram S, Agnihotri G, Gupta S. "The steady state analysis of Z-Source Inverter based Solar Power Generation System”, 2012 IEEE 5th India International Conference on Power Electronics, 2012,pp.1-6.

[5] http ://ww1.microchip.com/downloads/en/AppNotes/01444A.pdf 